\title{
The Relationship between Dance Music Structure and Dance Performance
}

\author{
Yang Cheng \\ Dalian Art College
}

Keywords: dance music; music structure; dance performance; part structure; melody structure; emotion structure

\begin{abstract}
It is generally believed that dance performance has nothing to do with dance music structure. However, in fact, dance performance is inseparable from dance music structure, and vice versa. The reason is that they supplement each other, and not a single one of them can be omitted. The beauty of art can only be presented when dance music is combined with dance performance properly; then, both visual and audio feelings can be generated inside people. This paper starts with "the research on dance music structure" as well as "the relationship between dance music structure and dance performance" in order to have a better understanding of "the relationship between dance music structure and dance performance".
\end{abstract}

\section{Introduction}

When actors are dancing, it will be very difficult for them to win audiences' favor if they merely rely on dance moves without the accompany of dance music, since performance in this way would appear "dull and boring". However, if there is merely the accompany of dance music without dance moves, it cannot be called "dance performance" at all. Therefore, during dance performance, dance music and dance performance need to be combined rationally, since they supplement each other, and a good combination of them two will be beneficial for the performance. Likewise, in order to create better effects of dance performance, a research on the relationship between dance music structure and dance performance, which is as follows.

\section{Investigation on Dance Music Structure}

Part structure of dance music belongs to the first part of music structure, the content of which is as follows: when dance music is divided according to part, it can be divided into symphony-style, one-part form, two-part form and three-part form. Normally speaking, the music structure of one-part form presents simple and easy dance. There is one more part in two-part form when compared with one-part form, so it can express more things. The music structure of three-part form is relatively complicated, so people usually apply it to dance arrangement, and it is used to express integrate music. Symphony-style music structure is related to symphony, so it has certain logic characteristics.

As is known that melody is an important part in music structure, since it can present the fluctuation of music. Generally speaking, melody can be divided into the following types, dialog mode, change mode, adversary mode, performance mode and ignorance mode. They have different effects. For example, change mode has characteristics of "change", i.e., the same piece of music can show different effects in different performance. Adversary mode has characteristics of "contrast", i.e., it can show contrast between dance music and dance performance. Performance mode can give actors opportunities to perform different dances according to their different feelings of dance music.

Only when dance music has "emotions" can it instigate performers' feelings, then performers can have emotional resonance for dance music. In the end, performers can sublimate their souls by dance music. On the contrary, music without emotions cannot create such effects, i.e., dance music without emotion structure is unfavorable for sublimating performers' dance moves, let alone the themes that dancers want to show. 


\section{Investigation on the Relationship between Dance Music Structure and Dance Performance}

Since dance music structure is briefly divided into three parts, when the relationship between dance music structure and dance performance is studied, the relationship between three "sub-structures" between dance music structure and dance performance should be studied first; then, the relationship between it and its content can be investigated. The investigation is as follows:

Since dance music part structure has different parts, there must be some differences between these several parts. In fact, their major different is that the music emotions they present is different. It is well-known that there are simple and complicated dance moves. When arrangers are arranging dance performance, he will combine music structure and music moves organically. Simple dance moves are combined with simple emotions, while complicated dance moves are combined with complicated emotions. In this way, not only performers' performance moves are shown better, music emotions in music structure are presented better, i.e., they supplement each other.

Take the famous dance performance Song of Tea-leaves Picking for example, which shows characteristics of parts of dance performance distinctly. This dance is divided into the part of "climbing the mountain", "tea-leaves picking" and "drinking-tea advising" part. In plots of "climbing the mountain", it presents the plots of "performers present different scenes of mountain-climbing with different dance teams"; during this period, performers dance while singing, presenting the scene of mountain-climbing skillfully. In the part of "tea-leaves picking", it presents "performers using different dance moves to show farmers' moves of tea-leaves picking and farmers' feelings of harvesting tea-leaves". During this period, performers use different moves and happy music to present this part well. In plots of "drinking-tea advising", it presents "performers using soft dance moves to show their expectations for beautiful life". During this period, moves and emotions are combined skillfully.

Dance music melody is composed of many elements, such as beat, harmony, rhythm and so on. Various kinds of music can be created if these elements are combined randomly. Therefore, dance performance is inseparable from dance music to some extent. In addition, proper combination of dance performance with dance music is not only beneficial to helping arrangers to arrange the dance, i.e., deep music melody with slow dance moves and lively music melody with "exaggerated" dance moves, but it is also conductive to helping performers to mode images, present personality and emotions. Therefore, dance melody can be used to set off dance performance, and dance performance can be used to present dance melody, i.e., they supplement each other, and they are conductive to presenting better effects.

It is well known that any piece of music has its unique emotions. However, when arrangers are arranging dance performance, they would consider the music emotions in the dance music, since only when the emotions agree with emotions in the dance music can resonance between dance performance and emotions be created, i.e., the arranged dance will create the relationship between dance music emotion structure and dance performance.

For example, music with simple emotions and melody like Moonlight over the Lotus Pond and Fly Freely are often applied in square dance. Normally speaking, moves of square dance are simple, and the emotions they show are monotonous. Therefore, music with monotonous emotions and simple melody should be matched. Only in this way can emotional resonance between dancers and dance music be generated. In addition, in the Sinkiang dance Why Are the Flowers So Red, they also supplement each other. This dance mainly wants to express the heroic and enthusiastic characteristics of Sinkiang girls as well as local national characteristics. Therefore, dancers' solid basic skills are needed to present the western style of the dance, since only in this way can flexibility and liveliness of minority be presented. In order to show the dance performance incisively and lively, dancers should not only rely on their basic skills, but also emotional characteristics of dance music, since only when resonance between dance music and dancers be created can the heroic and enthusiastic characteristics of Sinkiang girls as well as local national characteristics be created.

To some extent, there is something in common between dance and music, since both of them can be called art. Both of these two types of "art" are a kind of art that can entertain people. In addition, 
since dance moves are created based on dance music structure, dance music can direct people for dance performance. Therefore, if people want to enhance their music qualities, they would usually choose two ways, which are dance appreciation and music appreciation, since dance moves are related to dance rhythm. Dance music and dance moves are both important parts in dance performance.

Take the famous national dance Peacock Flying Over for example. In China, it is generally believed that peacock symbolizes elegance, nobility and beauty, so people usually imitate the beautiful postures of peacock to express their beautiful wishes. This national dance takes music with national flavors as the background music, which makes people feel as if they are personally on the scene; they are just like in nature, in which they can hear birds singing, see the woods and smell the fragrance of plants. Under the assistance of dance music, the dance moves become more incisive and vivid, thereby presenting emotions more sufficiently. Therefore, dance moves and dance music are important parts in dance performance. If dance moves are integrated into dance rhythm well, the performance is bound to be more splendid.

As is well known that if dancers want to present splendid performance, they need to grasp the timing of dance moves flexibly. However, if they want to do so, they need to change with changes of dance music rhythms. Therefore, people would choose the timing in dance performance according to timing in dance music. Generally speaking, people would choose soft parts as beginning of dance, since this part is beneficial to soften dancers' emotions. Actually, when arrangers are designing dance moves, they would consider the element of dance rhythm, since when hearing music rhythms, dancers can dance with the rhythm, grasp beats of dance moves and present better performance. Therefore, they supplement each other.

For example, in the famous national dance Song of Countryside, people choose the part of "little girl avoiding the rain" as the beginning timing, since this is the soft part. Therefore, when dancers are performing, they adopt soft moves to present this plot. In addition, in the plot of "little girl avoiding the rain", soft background music is also adopted. In the end, dancers present this part incisively and the little girl's enthusiasm and liveliness are shown vividly. Therefore, the dance performance is so successful mainly because the timing of dance moves agrees with the timing of dance music, so clear theme and distinct figure characteristics are presented.

\section{Conclusion}

Therefore, dance music structure is closely related to dance performance. They supplement each other and influence each other. If dance performance is separated from dance music, it would become "dull and boring" and cannot present the content that it wanted to present. If dance music is separated from dance performance, it would mean nothing. Therefore, both dance music and dance performance have their separate functions, and neither of them can be omitted. If dance music is combined perfectly with dance performance, excellent dance performance is bound to be presented and win audiences' great favor. To some extent, it can boost the development of dance art.

\section{References}

[1] Zhang Kunkun; The Relationship between Dance Music Structure and Dance Performance [J]; Journal of Minnan Normal University (Philosophy and social science edition); 2008(3)

[2] Xiao Yudan; The Relationship between Dance Music Structure and Dance Performance [J]; Home of Youth Literature; 2014(5)

[3] Li Guijuan: Investigation on Influences of Dance Music Structure on Dance Performance [J]; Research on Course Education; 2014(22)

[4] Luo Jie; On Function of Music in Dance Teaching[J]; China Education Innovation Herald; 2010(17)

[5] Lin Naizhen; Internal Emotions and External Images-On the Importance of Emotion in 
Dance Performance [J]; Art; 2009(04)

[6] Zhang Yao; On the Application of Dance Skills in Dance Performance[J]; Chinese After-school Education; 2012(07)

[7] Zhu Hong; Reflection on the Relationship between Music and Dance[J]; Journal of Yunnan Arts University; 2007(01)

Introduction to the author: Yang Cheng, teacher in Dalian Art College, majoring in music performance, lecturer, graduated from Shenyang Conservatory of Music, member of Dalian Dancer Association \& Liaoning Dancer Association 